\title{
A study on the Therapeutic Efficacy of Olopatadine Hydrochloride in the Management of Allergic Conjunctivitis
}

\author{
Chowdhury A N1, Hossain A K M M², Chowdhury M A H³, Chowdhury S H${ }^{4}$
}

\begin{abstract}
:
A prospective interventional study was conducted to see the efficacy and safety of a ophthalmic preparation olopatadine hydrochloride $(0.1 \%)$ on 40 allergic conjunctivitis patients attended the out-patient department of Ophthalmology, Sylhet M,A,G,Osmani Medical College Hospital. One drop of ophthalmic solution was administered 12 hourly in each eye for 2 weeks. Scoring of hyperaemia, itching, tearing, and photophobia were estimated before and 2 weeks after administration of the drug. After $30 \mathrm{~min} . \& 2$ weeks of administration of drug adverse effects were assessed if there was any. The mean scores of hyperaemia, tearing, itching and photophobia were reduced after 2 weeks of treatment. The scores of hyperaemia, itching, tearing, photophobia were found to be lower compared to Day 0. This change was statistically significant $(p<0.001)$. Olopatadine appeared to reduce ocular signs and symptoms in Allergic conjunctivitis .
\end{abstract}

Key words: Olopatadine hydrochloride, Allergic conjunctivitis, Hyperaemia, Tearing, Itching and Photophobia.

\section{INTRODUCTION}

Allergic eye disease affects about one-fifth of the world's population. Although the more advanced forms of the disease might be sight threatening, the most disabling effects are due to the clinical manifestations, with some patients having seasonal exacerbations of their symptoms, whereas others have symptoms that are present throughout the year ${ }^{1}$. The severity of the disease can range from mild itching and redness, as seen in seasonal allergic conjunctivitis, to the more severe, sight threatening forms such as vernal and atopic keratoconjunctivitis ${ }^{2}$. Thirty percent of the US population has some form of allergy; most of these patients have various target organs for their

Md. Abu Nayeem Chowdhury
Assisstant Professor Department of Pharmacology
Sylhet Women's Medical College, Sylhet.
2 A K M Mosharrof Hossain
Professor, Department of Pharmacology
Sylhet M.A.G. Osmani Medical College, Sylhet.
3. M A Hashem Choudhury
Associate Professor of Ophthalmology
Sylhet M.A.G. Osmani Medical College, Sylhet.
4. Shakhawat Hossain Chowdhury
Associate Professor of Ophthalmology
Sylhet M.A.G. Osmani Medical College, Sylhet.

allergies, and most have ocular involvement ${ }^{3}$. Seasonal allergic conjunctivitis (SAC) affects $15 \%$ of the UK population ${ }^{4}$, in spring when the predominant airborne allergen is tree pollen and in summer when the predominant allergen is grass pollen; or in fall when the predominant allergen is weed pollen 5 .

Allergic conjunctivitis is an immuno-pathological disease. It is a typical Type-1 hypersensitivity reaction mediated by $\mathrm{IgE}^{6}$. Conjunctival mast cell degranulation plays a major role in ocular allergic disease and so treatment option should be concentrated on preventing this process or of antagonizing the effects of the primary mediator, histamine ${ }^{7}$.

Topical antihistaminic agents not only provide faster and better relief than systemic antihistamines, but they may also possess a longer duration of action than other classes like pure mast cell stabilizers, NSAIDs and corticosteroids. Some topical multiple-action $\mathrm{H} 1$ receptor antagonists (olopatadine, ketotifen, azelastine and epinastine) have been shown to prevent activation of inflammatory cell and inhibit release of inflammatory mediators ${ }^{8}$. Olopatadine is a new selective $\mathrm{H} 1$ antagonist that has mast cell stabilizing properties and has been shown to affect release of mediators from conjunctival epithelial cells 9 .

H1 selectivity of olopatadine is superior to that of other ocular antihistamines ${ }^{10}$. Olopatadine hydrochloride $0.1 \%$ has a rapid onset of action and has strong, selective antihistaminic and mast cell stabilizing action. It is very well tolerated when instillated providing patients with rapid, effective and long lasting relief from the signs and symptoms of allergic conjunctivitis ${ }^{6}$

Now a day's treatment for allergic conjunctivitis has markedly expanded, providing more opportunities to choose a therapy but often leaving physicians confused over the variety of options. Information is limited about clinical outcome of patients with Allergic Conjunctivitis in our prospect. Lot of works have been done with olopatadine abroad, but so far we know there was no study done in our country regarding the effect of recently available drugs olopatadine on eye.

With this background, we designed to carry out this study to 
find out efficacy and safety of olopatadine hydrocloride in the treatment of allergic conjunctivitis.

\section{Materials and methods}

A prospective interventional study was carried out in the Department of Ophthalmology of Sylhet MAG Osmani Medical College Hospital. The patients who attended the ophthalmology out patient department of Sylhet MAG Osmani Medical College Hospital (SOMCH) with the diagnosis of acute allergic conjunctivitis were taken as the study subjects, as per inclusion criteria- a allergic conjunctivitis patient with hyperaemia, tearing, ocular itching and photophobia and exclusion criteria- associated with other systemic or ocular illness (bronchial asthma), eczema, dry eye, uveitis, infective conjunctivitis, receiving systemic or topical ocular medication, pregnancy etc as described by Aguilar 20006 Yaylali $^{11}$. After fulfilling the selection criteria, patients who were found to be eligible to include in the study, were selected randomly as every patient with even registered number received Olopatadine hydrochloride.

Patients appeared with the signs and symptoms of Allergic Conjunctivitis e.g.ocular itching, hyperaemia, dry eye, tearing, photophobia, pain eye, headache, mucus discharge, lid oedema etc. We studied on the patient with hyperaemia, tearing, ocular itching and photophobia in this single centre study as these signs \& symptoms were included in the previous studies ${ }^{6,11}$.

Every patient were given olopatadine hydrocloride $0.1 \%$, one drop in the each eye every $12 \mathrm{hrs}$. Scoring (Table-I) of hyperaemia, itching, tearing, and photophobia were recorded just before and after 2 weeks of drug therapy. During drug therapy the patients were instructed to report to Ophthalmology OPD (out patient department) or to contact with the chief investigator if any problem aroused; such as, foreign body sensation/stinging, headache, sedation, dry eye, worsening of symptoms/non response to therapy etc. Each patient was evaluated $30 \mathrm{~min}$ and 2 weeks after treatment initiation for side effect (Table-II).

Table-I: Scoring of signs and symptoms of allergic conjunctivitis

\begin{tabular}{|c|c|c|c|c|}
\hline \multirow{2}{*}{$\begin{array}{c}\text { Sign } \\
\text { Symptom }\end{array}$} & \multicolumn{4}{|c|}{ Sign Symptom Scoring of sign symptom of allergic conjunctivitis } \\
\hline & $\begin{array}{c}\text { Score } \\
\text { 0:Absent }\end{array}$ & $\begin{array}{l}\text { Score 1: } \\
\text { Mild }\end{array}$ & $\begin{array}{l}\text { Score 2: } \\
\text { Moderate }\end{array}$ & $\begin{array}{l}\text { Score 3: } \\
\text { Severe }\end{array}$ \\
\hline Hyperaemia & Absent & $\begin{array}{l}\text { Slightly dilated blood } \\
\text { vessels, pink in colour, }\end{array}$ & $\begin{array}{l}\text { More apparent vessel dilatation, } \\
\text { vessel colour is more intense, } \\
\text { involves most of vessel bed }\end{array}$ & $\begin{array}{l}\text { Numerous and obvious } \\
\text { dilated blood vessels, } \\
\text { colour deep red, }\end{array}$ \\
\hline Tearing & Absent & $\begin{array}{l}\text { Occasional, No complaints } \\
\text { of discomfort. }\end{array}$ & Frequent, patient felt as & $\begin{array}{l}\text { discomfort. Persistent } \\
\text { and frequently } \\
\text { accompanied by } \\
\text { swabbing of the eye }\end{array}$ \\
\hline Itching & Absent & $\begin{array}{l}\text { Occasional itching, } \\
\text { without tendency to } \\
\text { scratch or rub the eyes. }\end{array}$ & $\begin{array}{l}\text { Frequent } \\
\text { itching with tendency to } \\
\text { scratch or rub the eyes }\end{array}$ & $\begin{array}{l}\text { Continuous itching, } \\
\text { frequently rubbing } \\
\text { the eyes }\end{array}$ \\
\hline Photophobia & Absent & Occasionally photophobic & Continuously photophobic. & $\begin{array}{l}\text { Eye responds with } \\
\text { blepharospasm on } \\
\text { exposure to light }\end{array}$ \\
\hline
\end{tabular}


Table-II: Scoring of Side effect ${ }^{6}$

\begin{tabular}{|c|c|c|c|c|}
\hline \multirow{2}{*}{$\begin{array}{c}\text { Sign } \\
\text { effects }\end{array}$} & \multicolumn{4}{|c|}{ Scoring of Side effect of drug } \\
\hline & Score 0: & Score 1: & Score 2: & Score 3: \\
\hline $\begin{array}{l}\text { Stinging or } \\
\text { foreign body } \\
\text { sensation }\end{array}$ & Absent & $\begin{array}{l}\text { Mild: } \\
\text { Stinging or foreign body } \\
\text { sensation at instillation } \\
\text { only and disappears } \\
\text { rapidly }\end{array}$ & $\begin{array}{l}\text { Moderate : } \\
\text { Stinging or foreign body sensation } \\
\text { at instillation which persists but } \\
\text { treatment need not to be } \\
\text { discontinued }\end{array}$ & $\begin{array}{l}\text { Severe : } \\
\text { Stinging or foreign body } \\
\text { sensation at instillation } \\
\text { and persisting to the } \\
\text { point that treatment } \\
\text { has to be discontinued }\end{array}$ \\
\hline Headache & Absent & Present & & \\
\hline Sadation & Absent & Present & & \\
\hline Dry eye & Absent & Present & & \\
\hline
\end{tabular}

Study variables were signs and symptoms of allergic conjunctivitis e.g. Hyperaemia, Itching, Tearing, Photophobia. All statistical analyses were done by SPSS 12 version for windows software package. Values were expressed as mean \pm SD. 95\% significance level with $\mathrm{P}<\mathrm{O} . \mathrm{O} 5$ was taken as level of significance. Paired ' $\mathrm{t}$ '-test was done to see any significant difference between the scores of Day 0 \& 2 weeks after treatment.

Permission of the study was taken from the ethical committee of Sylhet MAG Osmani Medical College. Informed written consent was taken from the patients.

\section{OBSERVATION AND RESULTS}

The study was conducted on 40 patient with age range 12 to 50 yrs. mean age $28.33 \pm 10.9$ years and male female ratio was 9:11.

Effect of Olopatadine Hydrochloride on sign and symptoms of Allergic Conjunctivitis:

Before administration of Olopatadine hydrochloride hyperaemia score was recorded as $1.90 \pm 0.304$, while after 2 weeks it was recorded as $0.08 \pm 0.267$. The difference in hyperaemia score with administration of Olopatadine was statistically significant $(\mathrm{p}<0.001)$ and Olopatadine decreased hyperaemia by $95.78 \%$. [Table-III]

Tearing score, before administration of Olopatadine was $1.13 \pm 0.607$. After 2 weeks, tearing score was $0.03 \pm 0.158$. Olopatadine decreased tearing score significantly after 2 weeks $(p<0.001)$ and here reduction was $97.34 \%$. [TableIII]

Itching score, before administration of Olopatadine was $2.45 \pm 0.677,2$ weeks after administration score was recorded as $0.30 \pm 0.608$. These differences in itching scores before and after administration of Olopatadine was statistically significant $(\mathrm{p}<0.001)$. The decline in itching scores was $87.75 \%$. [Table-III]

2 weeks after administration of Olopatadine, photophobia was recorded $0.05 \pm 0.221$, while before initiation of treatment it was $1.27 \pm 0.452$. This changes between photophobia scores before and after administration of Olopatadine was statistically significant $(\mathrm{p}<0.001)$ and here the reduction in percentage scores of photophobia was 96.06\%. [Table-III]

Table-III:

Effect of Olopatadine Hydrochloride (0.1\%) administered at a dose of one drop 12 hourly on eye in patients suffering from Allergic Conjunctivitis and scores estimated after 2 weeks of instillation.

\begin{tabular}{|l|c|c|c|}
\hline \multirow{2}{*}{ Signs \& Symptoms } & \multicolumn{2}{|c|}{ Olopatadine-Treated } & \multirow{2}{*}{ Decrease in percentage } \\
\cline { 2 - 4 } & 0 week Mean scores \pm SD & 2 week Mean scores \pm SD & \\
\hline Hyperaemia $\mathrm{n}=40$ & $1.90 \pm 0.304$ & $0.08 \pm 0.267 *$ & $95.78 \%$ \\
\hline Tearing $\mathrm{n}=40$ & $1.13 \pm 0.607$ & $0.03 \pm 0.158^{*}$ & $97.34 \%$ \\
\hline Itching $\mathrm{n}=40$ & $2.45 \pm 0.677$ & $0.30 \pm 0.608^{*}$ & $87.75 \%$ \\
\hline Photophobia $\mathrm{n}=40$ & $1.27 \pm 0.452$ & $0.05 \pm 0.221^{*}$ & $96.06 \%$ \\
\hline
\end{tabular}


Significance of difference in efficacy scores of olopatadine estimated before (on 1st day) and 2 weeks after administration at $\mathrm{p}<0.001$ (Paired $\mathrm{t}$ - test).

\section{Adverse events:}

No adverse events e.g. stinging sensation, headache, sedation, dry eye, were observed during the study period.

\section{DISCUSSION:}

Allergic eye disease is a common problem in daily practice which affects more than $20 \%$ of the world's population and impairs their daily activities; the numbers of victims are increasing day by day along with the environmental pollution and ophthalmologists are practically facing it daily.

Allergic conjunctivitis hampers quality of life. The goal of treatment for seasonal allergic conjunctivitis is to effectively resolve clinical signs and symptoms, and improve quality of life. The pharmacotherapy of allergic conjunctivitis consists of several classes of drugs: antihistamines, mast cell stabilizers, dual-acting agents, NSAIDS and corticosteroids.

The aim of treatment of allergic conjunctivitis is to antagonize histamine activity and to maintain stabilization of mast cells. Therefore the dual-acting drug, olopatadine that combine histamine-receptor antagonism and mast cell stabilization are important to block histamine-related symptoms as well as prevention of mast-cell degranulation.

As a combination mast cell stabilizer / antihistamine, olopatadine is a relatively newer drug with better safety profile.

In our study olopatadine hydrochloride $0.1 \%$ solution was instillated as a dose of one drop in each eye 12 hourly and evaluated accordingly (as designed). Olopatadine appeared significantly effective compared to Day $0(p<0.001)$ in allergic conjunctivitis. This study showed that olopatadine significantly reduced signs and symptoms of allergic conjunctivitis from base line.

A doubled blind placebo control study by Abelson and Turner (2003)12 showed mean scores of ocular itching and hyperaemia were lower at all assessment times with olopatadine than placebo. The difference was statistically significant $(\mathrm{P}<0.05)$ for itching on days 7 and for both itching and hyperemia on days 14 . Our study also revealed that olopatadine is significantly effective against itching and hyperaemia after 2 weeks $(\mathrm{p}<0.001)$.

One hundred patients with previous history and current symptoms of seasonal or perennial allergic conjunctivitis were enrolled by Leonardi and Zafirakis $(2004)^{7}$ in a study of patient preference, a significantly greater percentage of patients $(81 \%)$ selected olopatadine when asked which medication they preferred; which they found more comfortable; which they found more efficacious in reducing symptoms of allergy. In our study, we scored s/s before treatment and after 2 weeks and our study result also showed that olopatadine is significantly effective and safe.

Behar and Kostic (2004) 13 also shown that Olopatadine $\mathrm{HCl}$ ophthalmic solution had an excellent tolerability profile; symptoms of ocular discomfort was reported in fewer than $5 \%$ in a clinical study. In our study none of 40 olopatadine treated subject complained such discomfort on eye. Olopatadine produced significant clinical improvement of study subjects by 2 week in every evaluated parameter without producing any adverse events. Therefore treatment goal was achieved by olopatadine safely.

In a double-masked, multi-centered, randomized trial by Artal, Luna and Discepola (2000) ${ }^{14}, 80$ subjects were asked to make a choice based on ocular comfort between one drop of olopatadine hydrochloride $0.1 \%$ instillated in one eye and one drop of ketotifen fumarate $0.05 \%$ instillated in the contralateral eye. All subjects $(100 \%)$ selected olopatadine as the more comfortable formulation. Our study design was different from this study but the result of our study showed that olopatadine is the more comfortable formulation. $100 \%$ of olopatadine treated group did not experience any adverse event. The treatment regimens were well tolerated.

A study from Uludag University, Bursa, Turkey showed that allergic conjunctivitis improved with topical olopatadine treatment (Dogru 2002)15. Another study showed that olopatadine and ketorolac ophthalmic solutions were found to be effective in alleviating the clinical signs and symptoms of Allergic Conjunctivitis compared to placebo, whereas olopatadine reduced ocular itching significantly more than ketorolac (Yaylali. 2003)11; Deschenes, Discepola and Abelson 199916) and cromolyn sodium (Katelaris 2002)17. A study that was done in Harvard Medical School, Boston showed that topical olopatadine therapy was significantly more efficacious than oral loratidine in reducing ocular itching related to allergic conjunctivitis (Abelson and Welch 2000)18. Result of our study also demonstrates that olopatadine exerted a better control on signs and symptoms of allergic conjunctivitis.

The use of olopatadine provides good status of eye with no apparent risk of adverse events. Ophthalmologist concerned with the treatment of allergic conjunctivitis may consider olopatadine for effective control of signs and symptoms of allergic conjunctivitis.

This study was conducted on a small number of patients and it was a single center trial. The findings would have been more significant if a placebo group could be used.

Further prospective interventional multi-centered placebo control trials are suggested for better assessment of the effective and safety therapeutic modalities that may improve the outcome of allergic conjunctivitis. 


\section{References:}

1. Manzouri B, Flynn TH Larkin F , Onoo SJ, Wyse R. 2006, 'Pharmacotherapy allergic eye disease', Expert Opinion on Pharmacotherapy, 7:1191-1200.

2. Leonardi A. 2005, 'Emerging drugs for ocular allergy', Expert Opinion on Emerging Drugs; 10:505-520.

3. Bielory L. 2000, 'Current reviews of allergy and clinical immunology', Journal of Allergy and Clinical Immunology, 106:1019-1032.

4. McGILL JI, Holgate ST, Church MK, Anderson DF. 1998, 'Allergic eye disease mechanisms', Br J Ophthalmol, 82:1203-1214.

5. Majmudar PA. (Last update November 4, 2005), 'Conjunctivitis, Allergic', [Online], eMedicine World Medical Library, Available from: http://www.emedicine.com/oph/topic85.htm [16 April 2007].

6. Aguilar AJ. 2000, 'Comparative Study of Clinical Efficacy and Tolerance in Seasonal Allergic Conjunctivitis Management with $0.1 \%$ Olopatadine Hydrochloride versus $0.05 \%$ Ketotifen Fumarate', Acta Ophthalmol Scand, 78:52-55.

7. Leonardi A, Zafirakis P. 2004, 'Efficacy and comfort of olopatadine versus ketotifen ophthalmic solutions: A double-masked, environmental study of patient preference', Current Medical Research \& Opinion, 20: 1167-1173.

8. McGill J. 2004, 'A review of the use of olopatadine in allergic conjunctivitis', International Ophthalmology, 25:171-179.

9. Leonard B, Kenneth WL, Steve B. 2005, 'Efficacy and Tolerability of Newer Antihistamines in the Treatment of Allergic Conjunctivitis', Drugs; 65:215-228.

10. Sharif NA, Xu SX, Miller ST, Gamache DA, Yanni JM. 1996, 'Characterization of the ocular antiallergic and antihistaminic effects of olopatadine (AL-4943A), a novel drug for treating ocular allergic diseases', American Society for Pharmacology and Experimental Therapeutics, 278:1252-1261
11. Yaylali V,Demirlenk I,Tatlipinar S,Ozbay D,Esme A,Yildirin C et al 2003, 'Comparative study of $0.1 \%$ olopatadine hydrochloride and $0.5 \%$ ketorolac tromethamine in the treatment of seasonal allergic conjunctivitis', Acta Ophthalmol Scand, 81:378-382.

12. Abelson MB,Turner D. 'A randomized, double-blind, parallel-group comparison of olopatadine $0.1 \%$ ophthalmic solution versus placebo for controlling the signs and symptoms of seasonal allergic', Clin Ther.2003; 25:931-947.

13. Behar L, Kostic D. 'Contemporary Management of Allergic Conjunctivitis', [Online], (31 March 2004); Pharmacy Times, 1065 Old Country Road, Westbury, NY11590.Available from : http://secure.pharmacytimes.com/lessons/html/conjunct 2001.htm [26 September 2007]

14. Artal MN, Luna JD, Discepola M. 'A Forced Choice Comfort Study of Olopatadine Hydrochloride $0.1 \%$ versus Ketotifen Fumarate 0.05\%, Acta Ophthalmol Scand, 2000;78:64-65.

15. Dogru M,Ozmen A,Erturk H,Sanli O,Karatas A. 'Changes in tear function and the ocular surface after topical olopatadine treatment for allergic conjunctivitis:an open-labe study', Clin Ther, 2002; 24:1309-1321.

16. Deschenes J, Discepola M, Abelson M. 1999, 'Comparative evaluation of olopatadine ophthalmic solution $(0.1 \%)$ versus ketorolac ophthalmic solution $(0.5 \%)$ using the provocative antigen challenge model', Acta Ophthalmol Scand Suppl, 228:47-52.

17. Katelaris CH,Ciprandi G,Missotten L,Turner FD,Bertin D, Berdeaux G. 'A Comparison Of Efficacy And Tolarability Of Olopatadine Hydrocloride $0.1 \%$ And Cromolyn Sodium 2\% In Seasonal Allergic Conjunctivitis', Clin Ther, 2002;24:1561-1575.

18. Abelson MB,Welch DL. 2000, 'An evaluation of onset and duration of action of patanol (olopatadine hydrochloride ophthalmic solution $0.1 \%$ ) compared to Claritin (loratadine $10 \mathrm{mg}$ ) tablets in acute allergic conjunctivitis in the conjunctival allergen challenge model', Acta Ophthalmol Scand Suppl, 230:60- 